\title{
Model of absorbed gamma radiation in the interaction with rock formation
}

\author{
A. A. Azaryan', A. N. Gritsenko' ${ }^{2}$ A. A. Trachuk ${ }^{1}$, V. M. Serebrenikov ${ }^{3}$, D. V. Shvets ${ }^{1 *}$ \\ ${ }^{1}$ Department of Modeling and Software, Kryvyy Rih National University, Ukraine \\ ${ }^{2}$ State Educational Institution, Kryvyy Rig National University, Ukraine \\ ${ }^{3}$ Department of Higher Mathematics and Information Systems, Donetsk National University of Economics and Trade \\ Named after M. Tugan-Baranovsky, Ukraine
}

\begin{tabular}{|c|c|}
\hline Article Info & ABSTRACT \\
\hline Article history: & \multirow{5}{*}{$\begin{array}{l}\text { The article discusses issues of improving the accuracy of operational quality } \\
\text { control of iron ore in mountain ranges. There was proposed the use of } \\
\text { the absorbed gamma radiation indicator as an improvement of the nuclear } \\
\text { physics method for determining the iron content in ore mass are proposed. } \\
\text { There were obtained the relationships of the sensitivity of the absorbed } \\
\text { gamma radiation intensity on the distance between the detector and } \\
\text { the irradiated surface, as well as on the distance between the source and } \\
\text { the detector of gamma radiation. }\end{array}$} \\
\hline Received Apr 21, 2019 & \\
\hline Revised Aug 22, 2019 & \\
\hline Accepted Oct 6, 2019 & \\
\hline Keywords: & \\
\hline
\end{tabular}

Absorbed gamma ray

Iron ore

Operational control

Copyright $@ 2019$ Institute of Advanced Engineering and Science. All rights reserved.

Corresponding Author:

D. V. Shvets,

Department of Modeling and Software,

Kryvyy Rih National University,

11 Vitaliya Matusevica str., Kryvyy Rih 50027, Ukraine.

Email: i.am.dmitriy.shvets@gmail.com

\section{INTRODUCTION}

Current requirements for the quality of mined iron ores indicate the need for both more accurate and operational determination of the iron content in them. One of the ways to improve the operational control of the iron content in the ore mass is the use of logging sonde (LS) in roller wells. In real conditions, measuring the iron content taking into account all the influencing factors on the accuracy of control is quite a challenge. One of the possible ways to overcome these difficulties is to use the result of the interaction of gamma radiation with iron ores as a source of information about the iron content. However, the intensity of the gamma-ray flux reflected from the rock mass used in the measurement does not carry enough information about the iron content, since this flux is rather small and characterizes the content of the useful component only in the surface layer of the array. In this regard, it seems appropriate when measuring the iron content in the ore to use the intensity of the flux of absorbed gamma radiation, which is much larger than the intensity of the reflected flux of gamma radiation, and largely characterizes the iron content within the ore body.

Analysis of the results of studies and publications on the control of iron content in ore arrays using LS in wells showed that in most cases insufficient attention is paid to the issues of measurement accuracy [1]. Nuclear physics methods for determining the content of the useful component in the ore were considered in works [2-4], where attempts were made to improve the accuracy of measurements depending on the number of gamma quanta reflected from the surface of the absorber. In work [5], the parameters of scintillation sensors for recording scattered gamma quanta are considered. Also in [3], a mathematical model was developed for determining the iron content in the ore by registering scattered gamma quanta. The authors of 
this article proposed accounting for absorbed gamma radiation in the irradiated material [6], which allows increasing the accuracy of determination of total iron in the ore under study.

In addition to nuclear physics methods for determining the iron content, magnetometer [7-9] and ultrasonic methods [10-12] are known. However, the magnetometer method allows determining the content of only magnetic iron in the studied rock mass and it is difficult to use ultrasonic control when logging explosive wells.

\section{RESEARCH METHOD}

The aim of the work is to improve the accuracy of operational quality control of mineral raw materials by using the intensity of absorbed gamma radiation. To achieve this goal, the following tasks were formulated:

- The choice of the parameters of the geometry of measuring the intensity of gamma radiation;

- Development of a functional scheme for the interaction of gamma radiation with a substance;

- Development of a mathematical model of the interaction of gamma radiation with a substance.

In modern conditions of iron ore mining, sufficient attention should be paid to issues related to the accuracy of measuring the iron content, which largely depends on the results of the interaction of the gammaradiation flux with the rock formation.

An analysis of the gamma-radiation flux absorbed by the ore mass, which is much larger than the reflected gamma-radiation flux used in modern devices, will make it possible to increase the accuracy of measuring the iron content in the ore. As one of the effective ways to implement the mathematical model of the interaction of gamma radiation with iron ore, which will allow to identify the main factors influencing the process of measuring the iron content in the ore mass. Due to the fact that at present considerable attention is paid to control methods that ensure an increase in the efficiency and reliability of the production process [13-14], these studies seem to be quite relevant.

\section{RESULTS AND ANALYSIS}

The gamma-gamma method based on the effect of the interaction of low-energy gamma-quanta with a substance is used to measure the content of total iron in the ore. The controlled ore mass is irradiated, and then the intensity of the integrated flux of scattered gamma radiation (the so-called Compton scattering) is recorded. A specific feature of modeling the measurement process is to build such a model that, with central geometry, would take into account the dependence of the intensity of the absorbed gamma-radiation flux on the geometric parameters: the distance between the radiation source and the detector, the distance between the detector and the reflecting surface.

It is logical to begin the synthesis of the model as a gauge of iron content in the ore with well-known and proven formulas describing the distribution of the gamma-radiation flux in the medium [15]. A diagram of the simulated interaction of gamma radiation with a substance is shown in Figure 1.

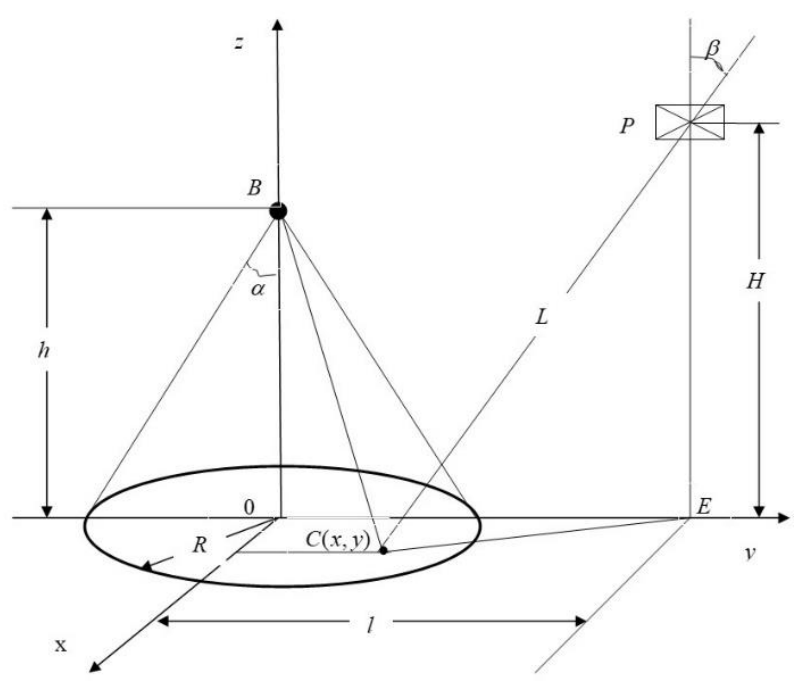

Figure 1. The scheme of interaction of gamma radiation with a substance 
The flow of gamma-quanta emanates from a point $B$ in the form of a circular cone with a solution angle of a cone $2^{*} \alpha$. Further, this stream reaches the irradiated surface, forming a "spot" in the form of a circle. Each point of this "spot" is a source of secondary (reflected) gamma radiation. Reflected gamma radiation carries the necessary information about the state of the array, which includes information about the content of iron in it $[3,5,16-20]$. The detector located at the point $P$ registers and measures the intensity of gamma radiation. According to the scheme of propagation of gamma radiation, presented in Figure 1, a gamma-quantum that reached an irradiated surface at a point $C(x, y)$, from an gamma-radiation source with an intensity $Q$ located at a point, is recorded as

$$
d N(x, y)=\frac{Q \cdot h}{\left(x^{2}+y^{2}+h^{2}\right)^{\frac{3}{2}}} d x d y
$$

where $Q$-gamma radiation source intensity, $1 / \mathrm{sec}, h$-distance from gamma radiation source to the irradiated surface, $m, d x d y$-area element in Cartesian coordinate system, $m^{2}$.

Then the total intensity of the gamma radiation flux reaching the surface is found by integrating over the region $\mathrm{D}$ in the form of a circle,

$$
N=Q \cdot h \iint_{D} \frac{d x d y}{\left(x^{2}+y^{2}+h^{2}\right)^{\frac{3}{2}}}
$$

To calculate the double integral, formula (2), it is necessary to reduce it to repeated integrals. The domain of integration $\mathrm{D}$ is bounded by a circle, the canonical equation of which has the form,

$$
x^{2}+y^{2}=R^{2}
$$

where $R$-the radius of the circle bounding the "spot" on the irradiation surface, $m$.

In the transition to polar coordinate $x=R \cdot \cos \varphi, y=R \cdot \sin \varphi$ formula (3) is written as

$$
r=R,(0 \leq \varphi<2 \cdot \pi)
$$

According to Equation (4) the integral, formula (2) takes the form

$$
N=Q \cdot h \iint_{D^{*}} \frac{1}{\left(r^{2}+h^{2}\right)^{\frac{3}{2}}} r d r d \varphi
$$

where $r d r d \varphi$ area element in polar coordinates, $m^{2}, D^{\bullet}=\{(r ; \varphi) \mid r=R ; 0 \leq \varphi<2 \cdot \pi\}-$ region of integration in polar coordinates.

To calculate the double integral, formula (5), we need to reduce it to repeated integrals. Given the integration boundaries, the double integral, formula (5) is written as

$$
N=Q \cdot h \int_{0}^{2 \cdot \pi} d \varphi \int_{0}^{R} \frac{r d r}{\left(r^{2}+h^{2}\right)^{\frac{3}{2}}}
$$

By integrating, we consistently find

$$
\begin{gathered}
N=\left.Q \cdot h \varphi\right|_{0} ^{2 \cdot \pi} \int_{0}^{R} \frac{1}{\left(r^{2}+h^{2}\right)^{\frac{3}{2}}} r d r=2 \pi \cdot Q \cdot h \int_{0}^{R} \frac{1}{\left(r^{2}+h^{2}\right)^{\frac{3}{2}}} r d r=\pi \cdot Q \cdot h \int_{0}^{R} \frac{1}{\left(r^{2}+h^{2}\right)^{\frac{3}{2}}} d r^{2}= \\
=-\left.2 \pi \cdot Q \cdot h \frac{1}{\left(r^{2}+h^{2}\right)^{\frac{1}{2}}}\right|_{0} ^{R}=-2 \pi \cdot Q \cdot h\left(\frac{1}{\left(R^{2}+h^{2}\right)^{\frac{1}{2}}}-\frac{1}{h}\right) \cdot
\end{gathered}
$$




$$
N=2 \pi \cdot Q \cdot\left(1-\frac{h}{\sqrt{R^{2}+h^{2}}}\right) .
$$

Taking into account that the radius of the "spot" circle on the irradiation surface is found by the formula $R=h \cdot \operatorname{tg} \alpha$. Formula (7) is consistently converted to

$$
\begin{aligned}
& N=2 \pi \cdot Q \cdot\left(1-\frac{h}{\sqrt{h^{2} \operatorname{tg}^{2} \alpha+h^{2}}}\right)=2 \pi \cdot Q \cdot\left(1-\frac{1}{\sqrt{1+\operatorname{tg}^{2} \alpha}}\right)=2 \pi \cdot Q \cdot\left(1-\cos ^{2} \alpha\right), \\
& N=2 \pi \cdot Q \cdot \sin ^{2} \alpha .
\end{aligned}
$$

Then the intensity of the flow of gamma radiation reflected from the surface is found by the formula

$$
M=2 \pi \cdot Q \cdot A \cdot \sin ^{2} \alpha
$$

where $A$-albedo coefficient.

The albedo coefficient A shows the fraction of the intensity of the flux incident on the surface of the irradiation reflected from the irradiated surface. It is obvious that the intensity of the absorbed gamma-ray flux can be found as the difference in formula (8) and (9)

$$
N_{n}=N-M \text { or } N_{n}=2 \pi \cdot Q \cdot \sin ^{2} \alpha \cdot(1-A)
$$

In turn, the element of the intensity of the flow of gamma radiation, defined by formula (1), is a source of secondary gamma radiation. In this case, the intensity of the secondary gamma-ray flux entering the detector located at a point $P$ from the point $C(x, y)$ is found by the formula:

$$
d M(x, y)=\frac{A \cdot h \cdot S}{L^{3}(x ; y)} d N(x, y)
$$

where $L(x, y)$-distance from point $C(x, y)$ to point $P$ of detector location, $\mathrm{m}, S$-detector area, $\mathrm{m}^{2}$.

According to the scheme of propagation of the flow of gamma radiation, presented in Figure 1, it is possible to record [21]

$$
L(x, y)=\sqrt{x^{2}+(l-y)^{2}+H^{2}}
$$

where $l-$ distance between radiation source and detector, $m$.

Taking into account (1) and (11), the formula (10) takes the form:

$$
d M(x, y)=\frac{Q \cdot A \cdot h \cdot H \cdot S}{\left(\left(x^{2}+y^{2}+h^{2}\right)\left(x^{2}+(l-y)^{2}+H^{2}\right)\right)^{1,5}} d x d y
$$

To find the total intensity of the secondary gamma radiation flux entering the detector, it is necessary to integrate over the region $D$

$$
M=Q \cdot A \cdot h \cdot H \cdot S \iint_{D} \frac{d x d y}{\left(\left(x^{2}+y^{2}+h^{2}\right)\left(x^{2}+(l-y)^{2}+H^{2}\right)\right)^{1,5}}
$$

To calculate the double integral formula (13), we need to reduce it to repeated integrals. By passing to the polar coordinates, the integral formula (14) is reduced to repeated integrals and takes the form: 


$$
\begin{aligned}
& M=Q \cdot A \cdot h \cdot H \cdot S \cdot \iint_{D^{*}} \frac{r d r d \varphi}{\left(\left(r^{2}+h^{2}\right)\left(r^{2} \cos ^{2} \varphi+(l-r \cdot \sin \varphi)^{2}+H^{2}\right)\right)^{1,5}}, \\
& M=Q \cdot A \cdot h \cdot H \cdot S \cdot \iint_{D^{*}} \frac{r d r d \varphi}{\left(\left(r^{2}+h^{2}\right)\left(r^{2} \cos ^{2} \varphi+l^{2}-2 l \cdot r \cdot \sin \varphi+r^{2} \sin ^{2} \varphi+H^{2}\right)\right)^{1,5}}, \\
& M=Q \cdot A \cdot h \cdot H \cdot S \cdot \int_{0}^{2 \cdot \pi} d \varphi \int_{0}^{h \cdot t g \alpha} \frac{r d r}{\left(\left(r^{2}+h^{2}\right)\left(r^{2}-2 r \cdot l \cdot \sin \varphi+l^{2}+H^{2}\right)\right)^{\frac{3}{2}}}
\end{aligned}
$$

Formula (15) allows finding the value of the albedo coefficient by the magnitude of the intensity of the flux of reflected gamma radiation measured by the detector,

$$
A=\frac{M}{Q \cdot h \cdot H \cdot S \int_{0}^{2 \cdot \pi} d \varphi \int_{0}^{h \cdot \operatorname{tg} \alpha} \frac{r d r}{\left(\left(r^{2}+h^{2}\right)\left(r^{2}-2 r l \sin \varphi+l^{2}+H^{2}\right)\right)^{1,5}}}
$$

Then, taking into account (16), formula (10) takes the form:

$$
N_{n}=2 \pi \cdot Q \cdot \sin ^{2} \alpha \cdot\left(1-\frac{M}{\left.Q \cdot h \cdot H \cdot S \cdot \int_{0}^{2 \cdot \pi} d \varphi \int_{0}^{h \cdot \operatorname{tg} \alpha} \frac{r d r}{\left(\left(r^{2}+h^{2}\right)\left(r^{2}-2 l \cdot r \sin \varphi+l^{2}+H^{2}\right)\right)^{1,5}}\right)}\right.
$$

Analysis of formula (17) shows that the intensity of the absorbed gamma-ray flux $N_{n}$ depends on seven variables: $Q, M, S, h, H, l, \alpha$. The study of formula (17) as a function of seven variables causes certain difficulties. Therefore, the question of the number of significant variables, defined as combinations of seven variables, is of exceptional importance. The application of the theory of similarity and analysis of dimensions [22] allows us to represent the formula (17) in the form

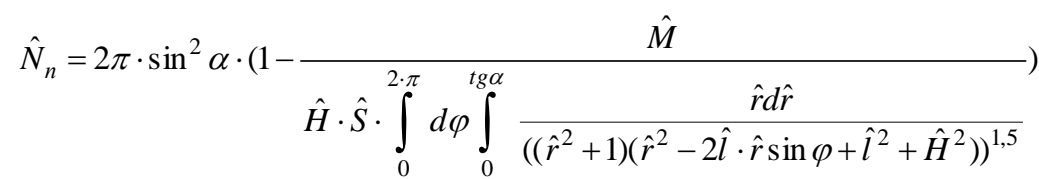

where $\hat{N}_{n}=\frac{N_{n}}{Q}, \hat{M}=\frac{M}{Q}, \hat{H}=\frac{H}{h}, \hat{r}=\frac{r}{h}, \hat{l}=\frac{l}{h}$. Analysis of formula (18) shows that the number of significant variables is five that is, decreased by two units [23].

In order to compare the magnitudes of the reflected and absorbed gamma radiation upon irradiation of the samples under conditions of central geometry, the corresponding numerical calculations were performed. For this purpose, the ratio formula (15) to (10) was compiled, allowing estimating the corresponding value in a dimensionless form

$$
E=\frac{A}{1-A} \frac{\hat{H} \cdot \hat{S}}{2 \pi \sin ^{2} \alpha} \int_{0}^{2 \cdot \pi} d \varphi \int_{0}^{\operatorname{tg} \alpha} \frac{\hat{r} d \hat{r}}{\left(\left(\hat{r}^{2}+1\right)\left(\hat{r}^{2}-2 \hat{r} \cdot \hat{l} \cdot \sin \varphi+\hat{l}^{2}+\hat{H}^{2}\right)\right)^{\frac{3}{2}}}
$$

where $\quad E=\frac{M}{N_{n}}, \hat{S}=\frac{S}{h^{2}}$.

Calculations using formula (19) were performed using the Mathcad software package [24]. In the calculations were taken such values of the parameters $\hat{H}=1, \hat{S}=0,7$. In Figure 2 shows the dependence diagram $E$ calculated by the formula (19), depending on the distance $\hat{l}$, for different values of albedo $A$. 


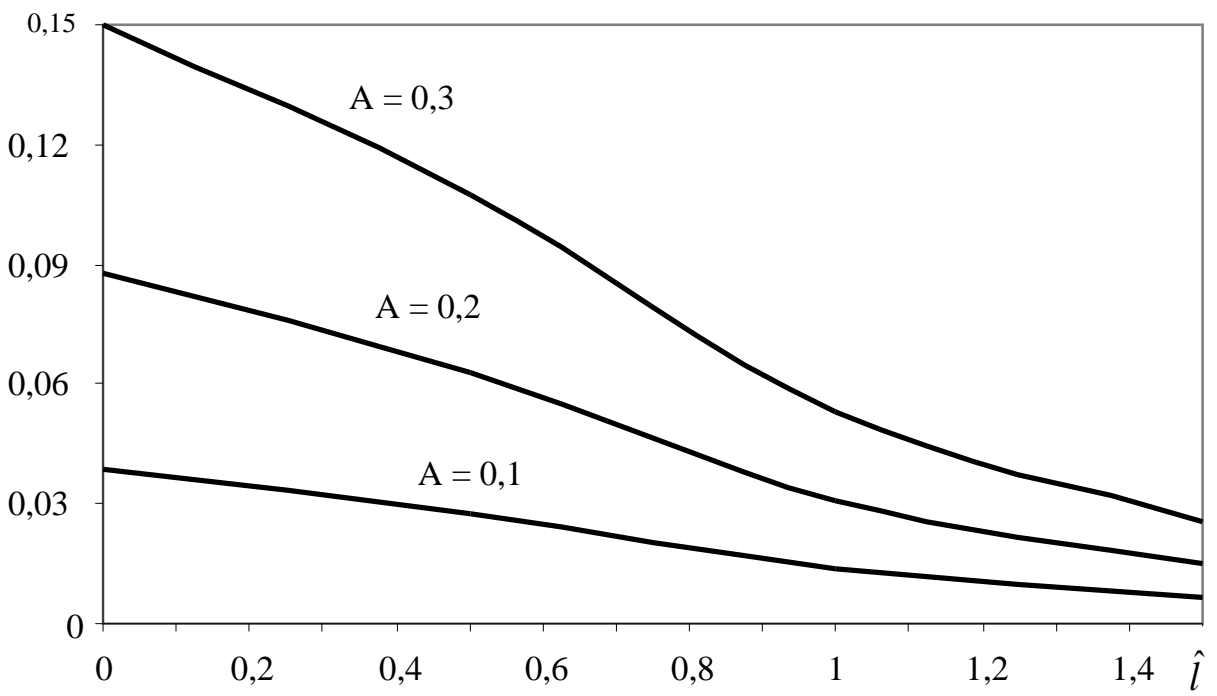

Figure 2. The dependent of the ratio $E$ from the distance $l$ at various values of a albedo

Analysis of the graphs shown in Figure 2 shows that the proportion of the reflected gamma-radiation intensity, as compared with the absorbed gamma-radiation intensity, decreases as the distance between the radiation source and the detector increases. Moreover, as the albedo decreases, this fraction becomes smaller. This result allows us to conclude that it is expedient to use the magnitude of the intensity of absorbed gamma radiation when measuring the iron content in the ore, since this leads to smaller errors. Estimation of the iron content in the ore should be carried out according to the formula (18), which, using information about the intensity of the reflected gamma-radiation flux makes it possible to calculate the intensity of the absorbed gamma-radiation flux, without the use of albedo.

Formula (18) allows us to estimate the sensitivity of the intensity of the absorbed gamma-ray flux with respect to the intensity of the reflected gamma-ray flux measured by the detector. For this, formula (18) is written a

$$
\frac{d N_{n}}{d M}=-\frac{2 \pi \cdot \sin ^{2} \alpha}{\hat{H} \cdot \hat{S} \cdot \int_{0}^{2 \cdot \pi} d \varphi \int_{0}^{\operatorname{tg} \alpha} \frac{\hat{r} d \hat{r}}{\left(\left(\hat{r}^{2}+1\right)\left(\hat{r}^{2}-2 \hat{l} \cdot \hat{r} \sin \varphi+\hat{l}^{2}+\hat{H}^{2}\right)\right)^{1,5}}}
$$

Figure 3. shows the results of calculations by the formula (20) with $\hat{S}=0,7$. 
$\left|\frac{d N_{n}}{d M}\right|$

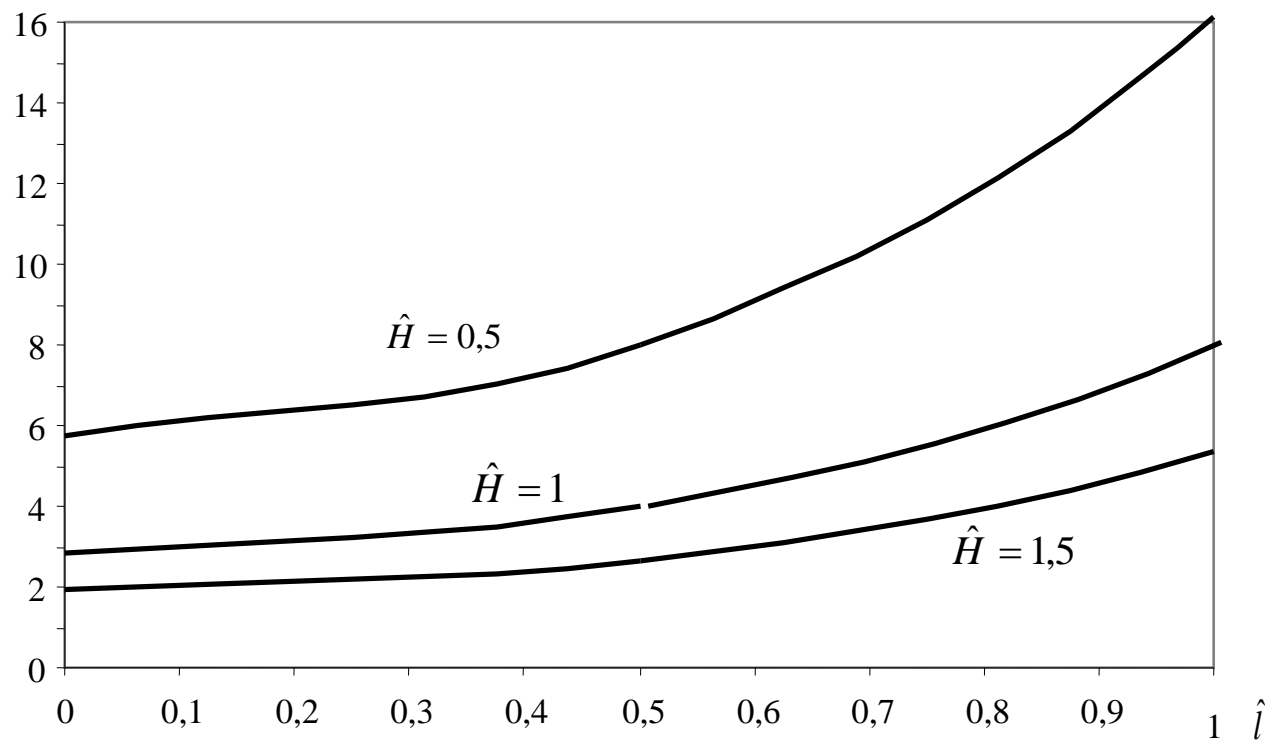

Figure 3. Dependence sensitivity from distance $\hat{l}(1-\hat{H}=0,5,2-\hat{H}=1,3-\hat{H}=1,5)$

\section{CONCLUSION}

With an increase in the distance between the source and the detector (sensor) of radiation, the proportion of reflected (scattered) radiation decreases sharply compared to the absorbed. As the distance between the source and the radiation detector increases, the sensitivity of the intensity of the absorbed gamma radiation increases by more than 2.5 times. As the distance from the detector to the irradiated surface decreases, the sensitivity under consideration also increases. For example, at $\hat{H}=1$ (the distance from the detector to the sample is equal to the distance from the source to the sample), the sensitivity increases from 3 at $\hat{l}=0$ to 8 at $\hat{l}=1$.

\section{REFERENCES}

[1] Azaryan and Gritsenko A. N., "Mobile Station for Logging of Blast Holes," Novi Technologii, no. (4), pp. 52-55, 2011.

[2] K. U. Kiran, et al., "Experimental and Simulated Study of Detector Collimation for a Portable 3" x 3" NaI (Tl) Detector System for in-Situ Measurements," Journal of Radiation Research and Applied Sciences, vol. 8, no. (4). pp. 597-605, 2015.

[3] A. Azaryan and V. Azaryan, "Use of Bourger Lambert Bera Law for the Operative Control and Quality Management of Mineral Raw Materials,” Metallurgical and Mining Industry, no. (1), pp. 4-9, 2015.

[4] Necati Çelik, Uğur Çevik, and Ahmet Çelik, "Effect of Detector Collimation on the Measured Mass Attenuation Coefficients of some Elements for 59.5-661.6 keV Gamma-Rays," Nuclear Instruments and Methods in Physics Research Section B: Beam Interactions with Materials and Atoms, vol. 281, pp. 8-14, 15 June 2012.

[5] A. Azaryan, "Research of Influence Single Crystal Thickness NaJ (TL) on the Intensity of the Integrated Flux of Scattered Gamma Radiation," Metallurgical and Mining Industry, no. (2). pp. 43-46, 2015.

[6] A. Azaryan, A. Gritsenko, A. Trachuk, and D. Shvets, "Development of a Method for Operational Control Over Quality of the Iron Ore Raw Materials during Open and Underground Extraction," Eastern-European Journal of Enterprise Technologies, Issue 5, no. (95), pp. 13-19, 2018.

[7] Shvets D. V., "Avtomaticheskoe Upravlenie Processom Izmel'chenija Magnetitovyh Rud na Osnove Opredelenija ih Prochnosti./Sbornik Nauchnyh Trudov,” Kachestvo Mineral'nogo Syr'ja, tom 2. Krivoj Rog., 2018.

[8] A. Azarjan, Dryga V. V., and Cybulevskij Ju. E., "Issledovanie Avtogeneratornogo Metoda Kontrolja Soderzhanija Zheleza Magnitnogo V Produktah Obogashhenija," Kachestvo Mineral'nogo Syr'ja: Sb. Nauch. Trudov. Akademija Gornyh Nauk Ukrainy, KTU, Ukrrudprom; Gl. Red. V. F. Byzov. Krivoj Rog. S. 117-123, 2005.

[9] A. Azaryan, Pikilnyak A., and Shvets D., "Complex Automation System of Iron Ore Preparation for Beneficiation," Metallurgical and Mining Industry, no. (8), pp. 64-66, 2015 
[10] V. Morkun, Morkun N., Tron V., and Hryshchenko S., "Investigation of the Effect of Characteristics of GasContaining Suspensions on the Parameters of the Process of Ultrasonic Wave Propagation," Eastern European Journal of Enterprise Technologies, no. 6, pp. 49-58, 2017.

[11] Porkujan O. V. And Sotnikova T. G., "Kombinirovannyj Metod Opredelenija Otnositel'nogo Soderzhanija Magnetita V Tverdoj Faze Zhelezorudnoj Pul'py,” Vestnik Nac. Tehn. Un-Ta "HPI, no. (12), pp. 29-36, 2010.

[12] V. Morkun, N. Morkun, A. Pikilnyak, "The Study of Volume Ultrasonic Waves Propagation in the Gas-Containing Iron Ore Pulp,” Ultrasonics, vol. 56, pp.340-343, 2015.

[13] Lutsenko I., Oksanych I., Shevchenko I., and Karabut N., "Development of the Method of Modeling Operational Processes for Tasks Relating to Decision-Making," Eastern-European Journal of Enterprise Technologies, vol. 2, Issue 4 (92), pp. 26-32, 2018.

[14] I. Lutsenko, E. Fomovskaya, I. Oksanych, E. Vikhrova, O. Serdiuk, "Formal Signs Determination of Efficiency Assessment Indicators for the Operation with the Distributed Parameters [Text]," Eastern-European Journal of Enterprise Technologies, vol. 1, Issue 4 (85), pp. 24-30, 2017.

[15] V. P. Mashkovich, A. V. Kudrjavceva A. V. M., "Zashhita ot Ionizirujushhih Izluchenij," Jenergoatomizdat, s. 495, 1995.

[16] C. Delwig et al., "Use of an Online Elemental Analyser to Optimize the Sinter Process at ThyssenKrupp Steel Europe, Duisburg, Germany," Proceedings Iron Ore Conference, Perth WA, The Australasian Institute of Mining and Metallurgy, Melbourne, pp. 381-388, 11-13 July 2011.

[17] Azarjan A. A. and Serebrenikov V. M., "Matematicheskoe Modelirovanie Jadernofizicheskih Metodov Analiza Hromovyh Rud," M. Gornyj Zhurnal, no. (6), s. 25-27, 1988.

[18] Sidney A. A. et. al., "Iron Ore Composition Monitoring using an Automated On-Line X-Ray Spectrometer Analyzer," URL: http://www.apc-analytics.com/sites/default/files/pdf_documents/isa_show_2008__solas_brauer_0.pdf (data zvernennja: 04.05.2018).

[19] A. Ya. Dzyublik et al., Mossbauer Forward Scattering Spectra of Ferromagnets in Radio-Frequency Magnetic Field," Jaderna Fizika Ta Energetika, t. 13, no. (1), s. 73-82, 2013.

[20] Shayakhmetov B. et al., "Studying Phase Structure of Burned Ferrous Manganese Ores by Method of Nuclear Gamma-Resonance Spectroscopy," Metallugiyja, vol. 53, no. (2), 2014

[21] V. S. Shipachev, "Kurs Vysshej Matematiki,” Izd-vo Mosk. un-ta, s. 280, 1981.

[22] A. A Guhman, "Vvedenie V Teoriju Podobija," Vysshaja shkola, s. 296, 1973.

[23] L. I. Sedov, "Metody Podobija I Razmernosti V Mehanike," Nauka, s. 432, 1987.

[24] E. G. Makarov, "Mathcad Uchebnyj Kurs,” Piter, s. 384, 2009.

Int J Rob \& Autom, Vol. 8, No. 4, December 2019: 269-276 